\title{
Finite element modelling of creep deformation in fibre-reinforced ceramic composites
}

\author{
Y. H. PARK, J. W. HOLMES \\ Ceramic Composites Research Laboratory, Department of Mechanical Engineering and Applied \\ Mechanics, The University of Michigan, Ann Arbor, MI 48109, USA
}

The tensile creep and creep-recovery behaviour of a unidirectional $\mathrm{SiC}$ fibre- $\mathrm{Si}_{3} \mathrm{~N}_{4}$ matrix composite was analysed using finite element techniques. The analysis, based on the elastic and creep properties of each constituent, considered the influence of fibre-matrix bonding and processing-related residual stresses on creep and creep-recovery behaviour. Both two- and threedimensional finite element models were used. Although both analyses predicted similar overall creep rates, three-dimensional stress analysis was required to obtain detailed information about the stress state in the vicinity of the fibre-matrix interface. The results of the analysis indicate that the tensile radial stress, which develops in the vicinity of the fibre-matrix interface after processing, rapidly decreases during the initial stages of creep. Both the predicted and experimental results for the composite show that $50 \%$ of the total creep strain which accumulated after $200 \mathrm{~h}$ at a stress of $200 \mathrm{MPa}$ and temperature of $1200^{\circ} \mathrm{C}$ is recovered within $25 \mathrm{~h}$ of unloading.

\section{Introduction}

Fibre-reinforced ceramic matrix composites (CMCs) are under development for use in high-temperature structural applications [1-4]. Owing to their recent development, however, only a limited number of experimental investigations of tensile creep behaviour have been conducted $[5,6]$. Thus, very little is currently known about the influence of composite microstructure on creep behaviour. Because experimental investigations of the elevated temperature creep behaviour of fibre-reinforced CMCs are costly and timeconsuming, there is a need first to understand and predict the creep deformation behaviour of CMCs as a function of the basic properties of each constituent.

Although the creep behaviour of metal matrix composites reinforced with continuous fibres $[7,8]$ and short fibres [9] has been modelled, the creep behaviour of continuous-fibre ceramic matrix composites has not been addressed. The purpose of the present paper is to discuss results obtained from a finite element investigation of the tensile creep and creeprecovery behaviour of a unidirectional $\mathrm{SiC}$-fibre $\mathrm{Si}_{3} \mathrm{~N}_{4}$-matrix composite formed by hot-pressing (HP$\left.\mathrm{SiC}_{\mathrm{f}} / \mathrm{Si}_{3} \mathrm{~N}_{4}\right)$.

\section{Modelling}

\subsection{Description of finite element mesh:} two- and three-dimensional analyses

\subsubsection{Two-dimensional finite element model}

The fibre packing in unidirectional fibre-reinforced ceramics can typically be idealized as either a hexagonal or rectangular array. Microstructural investiga- tions of the unidirectional $\mathrm{HP}-\mathrm{SiC}_{\mathrm{f}} / \mathrm{Si}_{3} \mathrm{~N}_{4}$ composites modelled in this study showed regions of both hexagonal and rectangular fibre packing (Fig. 1). In the present investigation, the fibre packing in HP$\mathrm{SiC}_{\mathrm{f}} / \mathrm{Si}_{3} \mathrm{~N}_{4}$ composites was approximated by a simple rectangular array. It has been shown that the type of fibre array has little effect on the stress-strain behaviour of continuous fibre-reinforced composites subjected to uniaxial loading parallel to the fibre axis [10].

Provided that the unit cell dimensions are small compared with the dimensions of the structure, the overall mechanical behaviour of a composite structure can be modelled by use of a geometric unit cell. For the two-dimensional analysis, a simplified coaxial cylindrical unit cell was used to investigate the overall creep behaviour of the composite. Fig. 2a shows the simplified coaxial cylinder unit cell, and Fig. $2 b$ shows the equivalent two-dimensional axisymmetric model which was used in the analysis. Because of symmetry, it was only necessary to model one-half of the unit cell. Two-dimensional, eight-node, quadrilateral axisymmetric elements were used in the analysis. As shown in Fig. $2 b$, the unit cell contains a fibre of radius $a$ which is surrounded by a matrix of radius $b$; The ratio $a^{2} / b^{2}$ corresponds to the volume fraction of the unit cell. In reality, the structure of SCS- 6 SiC fibres consists of a graphite-coated carbon core, diameter $\sim 33 \mu \mathrm{m}$, which is surrounded by a SiC sheath, outside diameter $142 \mu \mathrm{m}$. A thin $(\sim 3 \mu \mathrm{m})$ carbon-rich layer is typically applied to the $\mathrm{SiC}$ sheath. Under uniaxial tensile loading, the stresses carried by the carbon core and the carbon-rich layer are negligible because of their significantly lower elastic modulus compared to $\mathrm{SiC}$. 


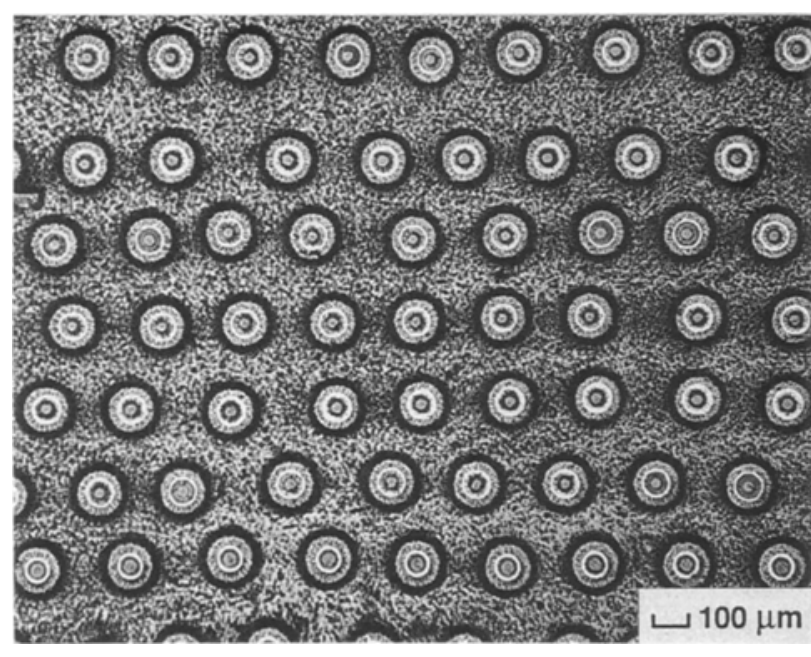

Figure 1 Optical micrograph showing regions of both hexagonal and rectangular fibre packing in $\mathrm{HP}-\mathrm{SiC}_{\mathrm{f}} / \mathrm{Si}_{3} \mathrm{~N}_{4}$ processed by hotpressing.

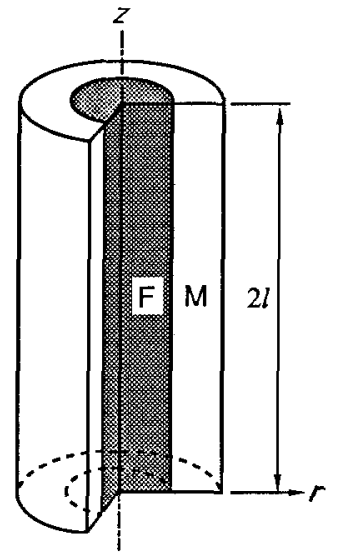

(a)

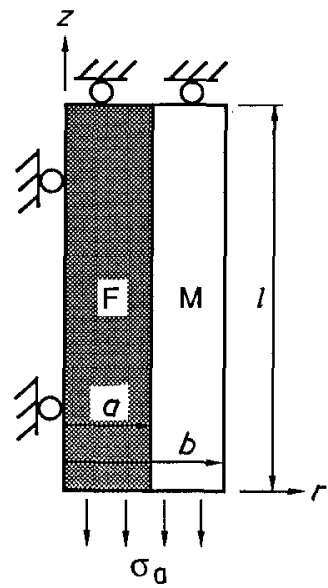

(b)

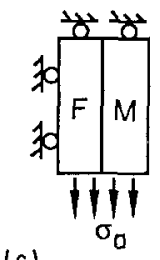

(c)

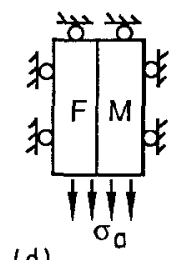

(d) priate selection of boundary conditions on the outer surfaces of the unit cell. The boundary conditions for the two-dimensional model are (see Fig. 2c)

$$
\begin{array}{lll}
U_{r}=0, & \tau=0 ; \text { on } r=0, & 0 \leqslant z \leqslant l \\
\frac{\mathrm{d} U_{z}}{\mathrm{~d} t}=0, & \tau=0 ; \text { on } z=0, & 0 \leqslant r \leqslant b \\
\frac{\mathrm{d} U_{r}}{\mathrm{~d} t}=0, & \tau=0 ; \text { on } r=b, & 0 \leqslant z \leqslant l \\
U_{z}=0, & \tau=0 ; \text { on } z=l, & 0 \leqslant r \leqslant b
\end{array}
$$

where $U_{z}$ and $U_{r}$ are the displacements in the axial and radial directions, respectively, and $\tau$ is the shear stress which acts parallel to the fibre axis. A constant average stress, $\sigma_{a}$, was remotely applied to the free end of the unit cell in a direction parallel to the fibre axis.

In a creep test conducted with cold grips, very little creep will occur in the cooler portions of the specimen near the grips. Moreover, the constraint provided from cooler portions of the specimen will tend to restrict the lateral movement of fibres within the gauge section. As an approximation, this constraint can be modelled by constraining the edge of the unit cell (which is physically located between two fibres, see Fig. 3) to have zero lateral displacement; as shown in Fig. 2d, the boundary condition along the edge of the unit cell $(r=b)$ becomes

$$
U_{\boldsymbol{r}}=0, \quad \tau=0 \text { on } r=b, \quad 0 \leqslant z \leqslant l
$$

(note that the other boundary conditions given by Equations 1a, b, and d remain unchanged). For all analyses, a fibre length-to-diameter ratio of 4 was used. This ratio was found to give results which were similar to those obtained using larger lengthto-diameter ratios.

\subsubsection{Three-dimensional finite element model}

In addition to the two-dimensional analysis described above, a three-dimensional analysis was performed in order to better understand the local stress distribution

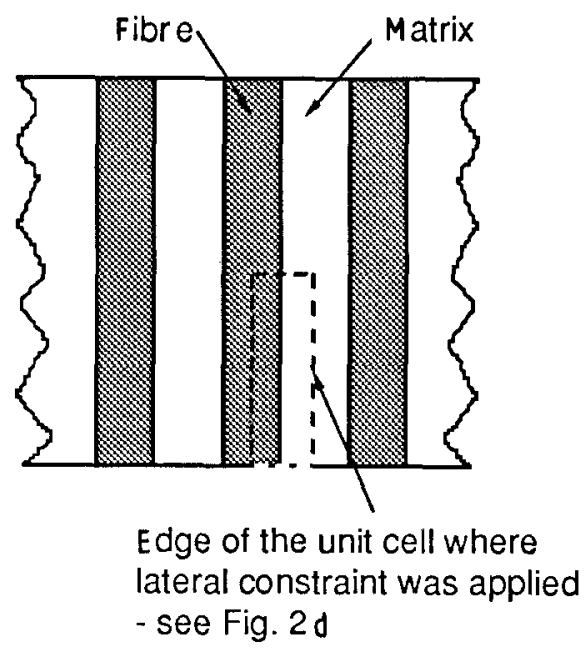

Figure 3 Schematic representation of a cross-section through a unidirectional composite. (- - ) The position of the finite element mesh used in the analysis. 
near the fibre/matrix interface, and to investigate the effect that transverse loading has on creep behaviour. The three-dimensional model assumed a rectangular array of fibres. The mesh used in the three-dimensional analysis is shown in Fig. 4. Three-dimensional eight-node quadrilateral elements were used for the majority of the mesh. To model the centre of the fibre, three-dimensional six-node triangular elements were used. The mesh contained a total of 800 elements. The three-dimensional model retained the same volume fraction and unit cell length as the two-dimensional axisymmetric model described above. The loading conditions and boundary conditions at the outer surfaces of the three-dimensional mesh were similar to those used in the two-dimensional analysis.

\subsection{Modelling interfacial behaviour}

SCS-6 SiC fibres have a higher coefficient of thermal expansion (CTE) than the $\mathrm{Si}_{3} \mathrm{~N}_{4}$ matrix $[11,12]$. As a consequence of this mismatch, radial tension develops normal to the fibre-matrix interface upon cooling of the billets after processing. If the degree of chemical bonding at the interface is weak, the radial tension which develops during cooling can cause partial or complete debonding along the fibre-matrix interface. The initial interfacial stress state which exists in a composite depends upon the fabrication route and interfacial chemistry used to produce the composite. For example, initial debonding in reaction-bonded $\mathrm{SiC}_{\mathrm{f}} / \mathrm{Si}_{3} \mathrm{~N}_{4}$ composites was observed by Laughner and Bhatt [13]; whereas initial debonding was absent in hot-pressed $\mathrm{SiC}_{\mathrm{f}} \mathrm{Si}_{3} \mathrm{~N}_{4}$ composites investigated by Holmes [6]. Results obtained from fibre push-out tests show the existence of an interfacial shear stress in $\mathrm{SiC}_{\mathrm{f}} / \mathrm{Si}_{3} \mathrm{~N}_{4}$ composites, even after complete debonding along the interface has occurred $[13,14]$. As noted by Morscher et al. [14], this interfacial shear stress is caused by surface roughness along the fibre-matrix interface.
In the present study, two idealized limiting cases of interfacial bonding were considered: (i) perfectly bonded fibre-matrix interfaces, and (ii) completely debonded interfaces. In both cases, the interface was assumed to be smooth. It was further assumed that complete load transfer occurs outside the gaugesection of the creep specimen. Thus, for a unit cell located within the gauge section, the axial strain in the fibre and matrix are the same, i.e. isostrain conditions are present. Interface elements were used in the finite element analysis [15]. These interface elements allow both normal and shear stress to be transmitted along the fibre-matrix interface (note that in the present analysis the interfacial shear is zero because complete load transfer is assumed to occur outside the gaugesection).

\section{Constitutive equations and properties}

As in metals, the creep rate of ceramics is a function of applied stress, temperature, and time, i.e. $\dot{\varepsilon}=f(\sigma, T, t)$. Because the creep strains in monolithic ceramics are significantly smaller than those in metals, and are further reduced by the presence of reinforcing fibres in ceramic composites, the primary creep behaviour of fibre-reinforced CMCs cannot be ignored. For many ceramics, the steady-state creep rate can be described by a simple power law function of the applied stress, where the stress exponent depends upon the creep deformation mechanism. Several experimental investigations indicate that the steady-state creep behaviour of whisker-reinforced CMCs $[16,17]$ and fibre-reinforced CMCs $[5,6,18]$ can also be approximated by a simple power law. Ceramics which do not exhibit steady-state creep behaviour can sometimes be described by viscoelastic or other anelastic equations.

The composite system chosen for the analytical investigation was comprised of SCS- $6 \mathrm{SiC}$ fibres in a hot-pressed $\mathrm{Si}_{3} \mathrm{~N}_{4}$ matrix. The analysis considered

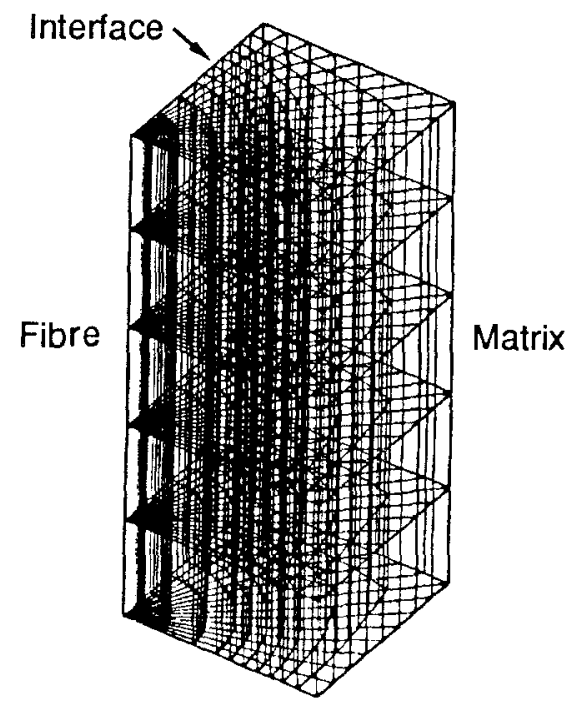

(a)

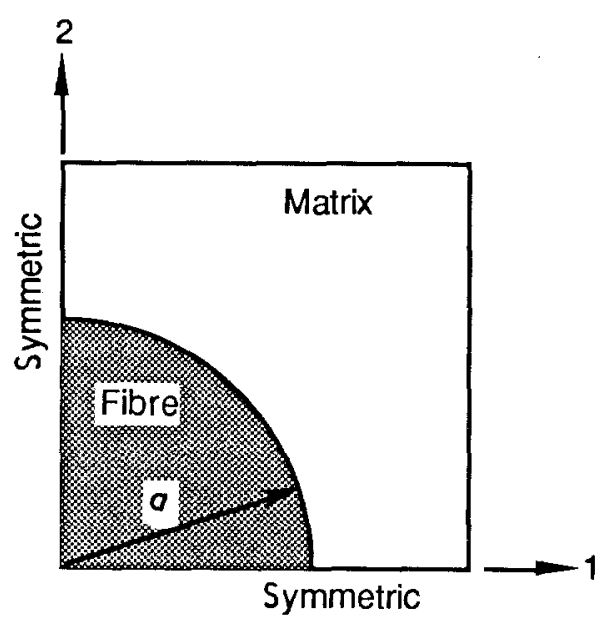

(b)

Figure 4 (a) Rectangular unit cell used in the three-dimensional finite element analysis of creep deformation. (b) Cross-sectional view through the three-dimensional unit cell. The boundary conditions are similar to those used in the two-dimensional model. 
unidirectional reinforcement only. The creep behaviour of SCS- 6 SiC fibres has been studied in detail by Dicarlo [11]. For temperatures up to $1400^{\circ} \mathrm{C}$, and stress levels below $600 \mathrm{MPa}$, Dicarlo found an approximately linear dependence of creep strain on applied stress. Based upon the characteristic of anelastic deformation, the creep deformation behaviour of SCS$6 \mathrm{SiC}$ fibres at constant temperature can be described by the following equation

$$
\dot{\varepsilon}=A \sigma^{n} t^{m}
$$

where $A$ is a stress-independent constant, and $n$ and $m$ are constants $(-1<m \leqslant 0)$. Using Dicarlo's data [11], at $1200^{\circ} \mathrm{C}$ the constants in Equation 2 were estimated as follows: $n=1, \quad m=-0.667$, and $A=7.2 \times 10^{-15}$ (for $\sigma(\mathrm{Pa})$ and $t(\mathrm{~s})$ ). The non-zero value of $m$ suggests a continuously decreasing creep rate with time (i.e. steady-state creep is absent). Notice that Equation 2 can also be used to describe the primary creep behaviour of the fibre.

For monolithic ceramics which exhibit steady-state creep, the total creep rate, $\dot{\varepsilon}_{\mathrm{c}}$, can be expressed as the sum of the primary creep rate, $\dot{\varepsilon}_{\mathrm{p}}$, and the steady-state creep rate, $\dot{\varepsilon}_{\mathrm{s}}$, i.e.

$$
\dot{\varepsilon}_{\mathrm{c}}=\dot{\varepsilon}_{\mathrm{p}}+\dot{\varepsilon}_{\mathrm{s}}
$$

where $\dot{\varepsilon}_{\mathrm{p}}=0$ in the steady-state region. Primary and steady-state tensile creep data were not available for the hot-pressed $\mathrm{Si}_{3} \mathrm{~N}_{4}$ matrix of the $\mathrm{HP}-\mathrm{SiC}_{\mathrm{f}} / \mathrm{Si}_{3} \mathrm{~N}_{4}$ composite which was experimentally investigated (the matrix contained $5 \mathrm{wt} \% \mathrm{Y}_{2} \mathrm{O}_{3}$ and $1.25 \mathrm{wt} \% \mathrm{MgO}$ as sintering aids). For the temperature of interest, the only available data for the primary creep of hotpressed $\mathrm{Si}_{3} \mathrm{~N}_{4}$ is that given by Fett et al. [19] for a $3 \mathrm{wt} \% \mathrm{MgO}-\mathrm{HPSN}$. Fett et al.'s [19] data were obtained from four-point bending tests, and may therefore underestimate the tensile creep rate of the matrix. However, as discussed later, because the creep rate of the fibre is much lower than that of the matrix, the long-term creep rate of the composite is relatively insensitive to the precise primary creep rate used in the analysis.

As an approximation, the primary creep of the $\mathrm{Si}_{3} \mathrm{~N}_{4}$ matrix was modelled using the following empirical relationship which was proposed by Fett et al. [19]

$$
\dot{\varepsilon}_{\mathrm{p}}=C_{1} \sigma^{n_{1}} \varepsilon_{\mathrm{p}}^{-\mathrm{p}}\left(C_{2} \sigma^{n_{2}}-\varepsilon_{\mathrm{p}}\right)
$$

To model the steady-state creep rate of the matrix, temperature-compensated data given by Kossowsky et al. [20] for HS-130 $\mathrm{Si}_{3} \mathrm{~N}_{4}$ (which does not contain $\mathrm{Y}_{2} \mathrm{O}_{3}$ ) at $1200^{\circ} \mathrm{C}$ was used. The steady-state creep rate was modelled using a simple power law

$$
\dot{\varepsilon}_{\mathrm{s}}=B \sigma^{n}
$$

From analysis of Kossowsky et al.'s data [20], the constants in Equation 5 were estimated as $n=2$ and $B=2.833 \times 10^{-25}$ (for $\sigma(\mathrm{Pa})$ and $t(\mathrm{~s})$ ). The steadystate creep data are valid for stresses between 70 and $110 \mathrm{MPa}$. In the analysis, it was assumed that the same constants ( $n$ and $B$ ) hold for stresses below 70 MPa. Equations 2, 4 and 5 were implemented in the commercial finite element code (ABAQUS) [15].
Throughout the analysis, the hot-pressing temperature was taken as $1700^{\circ} \mathrm{C}$ (note that the hot-pressing temperature influences the initial residual stress-state of the composite).

Data for Young's modulus, Poisson's ratio, and the coefficient of thermal expansion of SCS-6 SiC fibres and hot-pressed $\mathrm{Si}_{3} \mathrm{~N}_{4}$ were obtained from the experimental results of other investigators $[11,12,20]$. At $1200^{\circ} \mathrm{C}$, the data used in the analysis were $E_{\mathrm{f}}=367$ $\mathrm{GPa}, E_{\mathrm{m}}=274 \mathrm{GPa}, V_{\mathrm{f}}=0.3, V_{\mathrm{m}}=0.7, v_{\mathrm{f}}=0.17$, $v_{\mathrm{m}}=0.27 \alpha_{\mathrm{f}}=5.5 \times 10^{-6}{ }^{\circ} \mathrm{C}^{-1}, \alpha_{\mathrm{m}}=3.2 \times 10^{-6}{ }^{\circ} \mathrm{C}^{-1}$, where $E$ is Young's modulus, $V$ is volume fraction, $v$ is Poisson's ratio, and $\alpha$ is the coefficient of thermal expansion (the suffices $f$ and $m$ denote fibre and matrix, respectively). To determine the validity of the finite element model and the creep equations used for the fibre and matrix, the finite-element model was assumed to be homogeneous (either SiC fibre or monolitbic $\mathrm{Si}_{3} \mathrm{~N}_{4}$ ) and the predicted creep behaviour was compared with the known creep behaviour of each constituent. In both cases, agreement was found between the finite element results and the experimental results.

\section{Experimental procedure}

For comparison with the finite element results, a limited number of tensile creep and creep-recovery tests were conducted using unidirectional $\mathrm{HP}-\mathrm{SiC}_{\mathrm{f}} / \mathrm{Si}_{3} \mathrm{~N}_{4}$. The composites were processed by two different techniques: (1) dry-powder lay-up, and (2) tape casting. For both fabrication routes, the composite was processed with 30 vol $\%$ SCS-6 SiC fibres. The $\mathrm{Si}_{3} \mathrm{~N}_{4}$ matrix contained $5 \mathrm{wt} \% \mathrm{Y}_{2} \mathrm{O}_{3}$ and $1.25 \mathrm{wt} \% \mathrm{MgO}$ as sintering aids. The dry-powder lay-up composite, which was hot-pressed at $1700^{\circ} \mathrm{C}$, had a density close to $99 \%$ theoretical density for this system. The tapecast composite had a density of approximately $97 \%$. All experiments were conducted on a servohydraulic load frame fitted with self-aligning grips to minimize the bending strains imposed on the specimen through misalignment of the load train. Details of the testing procedure and edge-loaded specimen geometry used in the experiments can be found elsewhere $[6,18,21]$. The $1200^{\circ} \mathrm{C}$ creep experiments were conducted in air at an applied stress of $200 \mathrm{MPa}$, which is approximately $20 \mathrm{MPa}$ above the proportional limit of the dry-powder lay-up composite [18], but below that of the tape-cast composite (see Fig. 5). (The proportional limit is defined as the initial departure from linearity in the monotonic tensile stress-strain curve. Physically, the proportional limit corresponds to a detectable amount of matrix cracking). After $200 \mathrm{~h}$ of creep, the tape-cast specimens were unloaded to investigate the creep-recovery behaviour of the composite (the specimens were unloaded at a rate of $100 \mathrm{MPa} \mathrm{s}^{-1}$ ).

\section{Results and discussion}

Fig. 6 shows the creep behaviour predicted for a HP$\mathrm{SiC}_{\mathrm{f}} / \mathrm{Si}_{3} \mathrm{~N}_{4}$ composite containing $30 \mathrm{vol} \%$ fibres. The analysis was performed assuming a temperature of $1200^{\circ} \mathrm{C}$ and an applied stress of $180 \mathrm{MPa}$. There was 


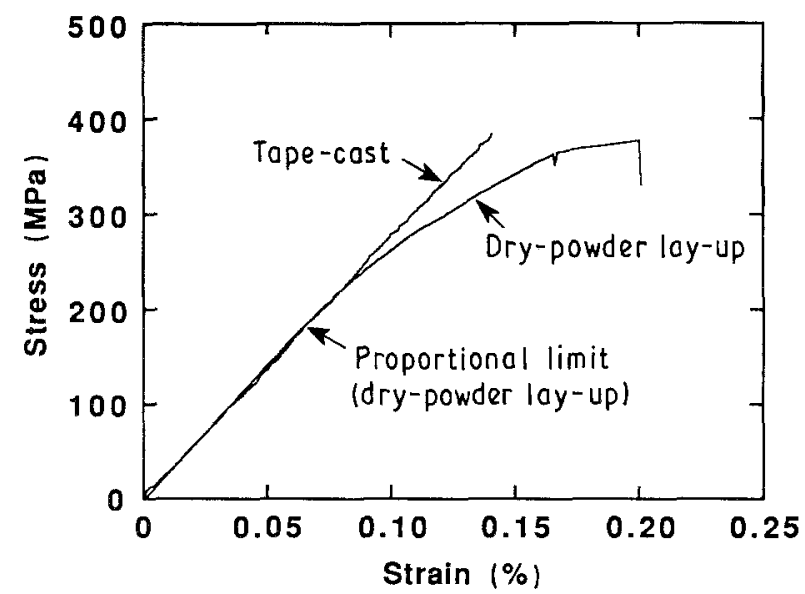

Figure 5 Monotonic tensile behaviour of $0^{\circ} \mathrm{HP}-\mathrm{SiC}_{\mathrm{f}} / \mathrm{Si}_{3} \mathrm{~N}_{4}$ (30 vol \%) tested in air at $1200^{\circ} \mathrm{C}$. To avoid creep deformation, the tensile tests were conducted at a loading rate of $100 \mathrm{MPa} \mathrm{s}^{-1}$.

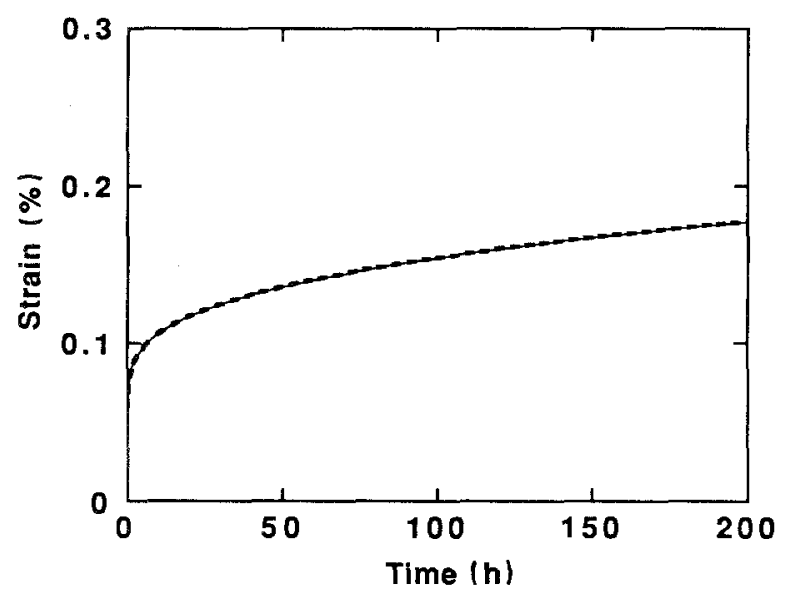

Figure 6 Comparison of the tensile creep behaviour of $0^{\circ} \mathrm{HP}-$ $\mathrm{SiC}_{\mathrm{f}} / \mathrm{Si}_{3} \mathrm{~N}_{4}(30 \mathrm{vol} \%)$ predicted using ( - ) two- and (-- $)$ threedimensional finite element models (the curves shown assumed perfect bonding along the interface). The deviation between the two models was less than $1 \%$ for all strains.

typically less than a $1 \%$ difference in the $\varepsilon-t$ curves predicted using the two- and three-dimensional models. Although the two- and three-dimensional models provided similar results for overall creep behaviour, it was necessary to use a three-dimensional analysis when accurate information concerning the stress distribution in the composite was required. It was also necessary to use a three-dimensional analysis when considering biaxial loading histories. Compared to the results obtained from an analysis where it was assumed that only the fibres undergo primary creep, when the primary creep of the matrix is included in the model, the total creep strain of the composite increases and the duration of primary creep is reduced (see Fig. 7). However, including the primary creep behaviour of the matrix does not significantly influence the predicted quasi steady-state creep rate of the composite. (The predicted creep behaviour of the composite did not exhibit steady-state creep, but rather a continuously decreasing creep rate. This result is a consequence of the constitutive equation which was used in the analysis for fibre behaviour, which exhibited a continuously decreasing creep rate, i.e. exponent

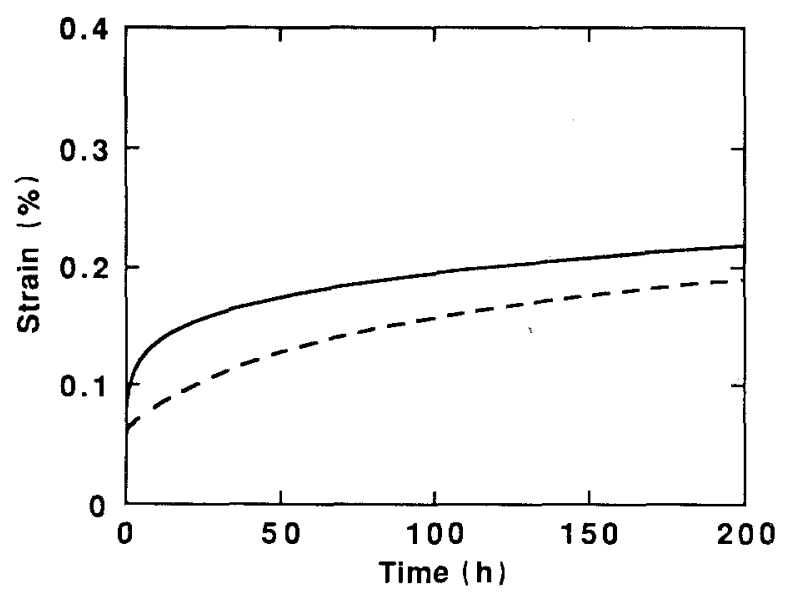

Figure 7 Importance of including the primary creep behaviour of both constituents. (-) Primary creep for both the fibre and matrix, $(---)$ primary creep for the fibre only. The analysis assumed 30 vol $\%$ fibres.

$m \neq 0$ in Equation 2. For purposes of discussion, the region over which the creep rate slowly decreases will be referred to as the quasi steady-state regime.) In the present analysis, all predictions include primary creep for both the fibre and matrix. Unless otherwise noted, the results presented were obtained from a two-dimensional analysis with the boundary condition of no lateral constraint along the sides of the mesh.

\subsection{Influence of interface condition}

Fig. 8 compares the difference in creep behaviour predicted for perfectly bonded and completely debonded interfaces. In both cases, the applied stress was $180 \mathrm{MPa}$. For the case of perfect bonding, the residual stresses developed upon cooling from the hot-pressing temperature of $1700^{\circ} \mathrm{C}$, to the creep temperature of $1200^{\circ} \mathrm{C}$, were included in the analysis (note that these residual stresses are absent in the case of complete debonding). For the case of perfect bonding, the consideration of residual thermal stresses caused a large decrease in the primary creep rate of the composite, which significantly reduced the total creep strain attained in $200 \mathrm{~h}$ (Fig. 8). This reduction in primary creep rate is a consequence of the initial residual axial

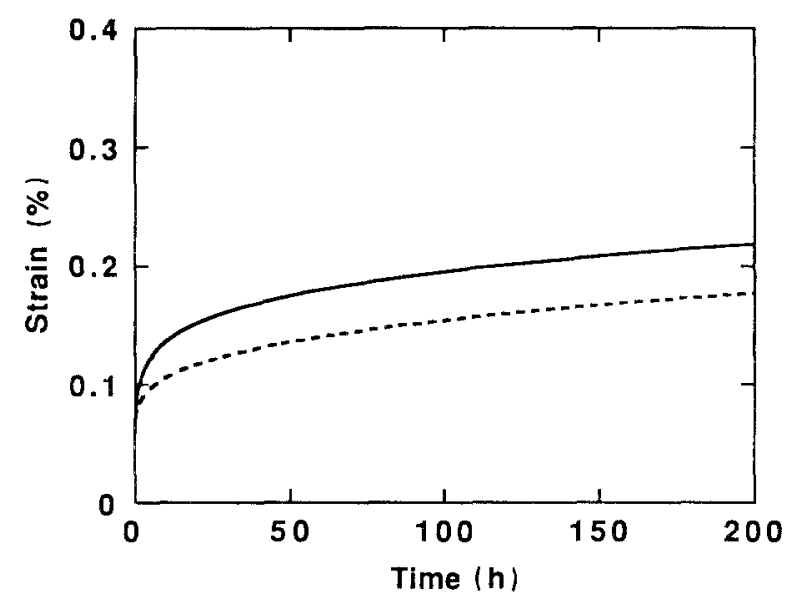

Figure 8 Comparison of the tensile creep behaviour of $\mathrm{HP}-\mathrm{SiC}_{\mathbf{f}} /$ $\mathrm{Si}_{3} \mathrm{~N}_{4}(30 \mathrm{vol} \%)$ predicted for $(--)$ perfectly bonded and (-) debonded interfaces. 
compressive stress which develops in the matrix upon cooling from the processing temperature. Although the overall creep strain was larger for the debonded case, the creep rates in the quasi steady-state region were similar for perfectly bonded and debonded interfaces. This similarity in quasi steady-state creep rate is attributed to the rapid relaxation of matrix stress, which in both cases approaches nearly the same limiting value within $50 \mathrm{~h}$. The time-dependent change in axial matrix stress near the interface is illustrated in Fig. 9 for both the bonded and debonded interfaces.

\subsection{Effect of fibre-reinforcement and volume fraction}

Fig. 10 compares the creep behaviour of monolithic $\mathrm{Si}_{3} \mathrm{~N}_{4}$ with that predicted for unidirectional HP$\mathrm{SiC}_{\mathrm{f}} / \mathrm{Si}_{3} \mathrm{~N}_{4}$ composites containing 15 and $30 \mathrm{vol} \%$ SCS-6 SiC fibres (hereafter, a debonded interface was assumed in the analysis). The comparison was made at $1200^{\circ} \mathrm{C}$ and an applied tensile stress of $180 \mathrm{MPa}$, which is below the matrix cracking stress typically found for both the tape-cast and dry-powder lay-up

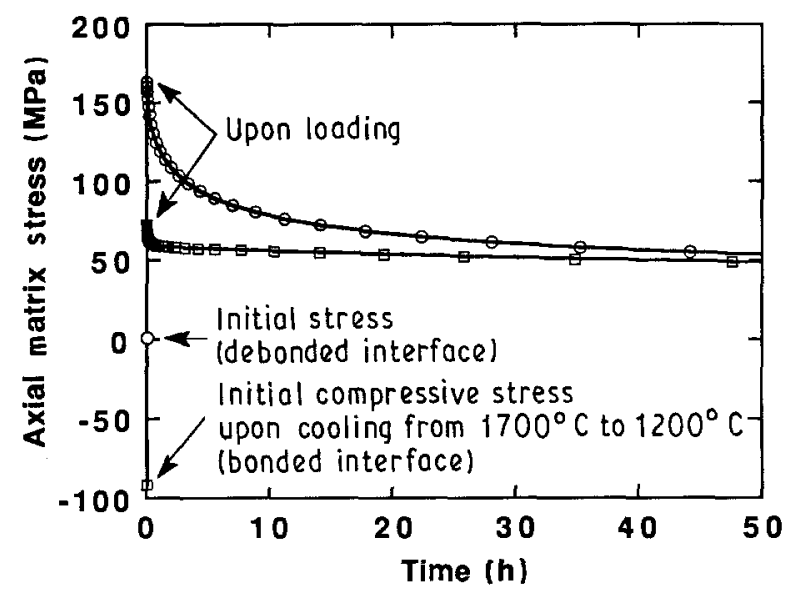

Figure 9 Relaxation of axial stress in the matrix near the interface at $1200^{\circ} \mathrm{C}$ and $180 \mathrm{MPa}(\square)$ bonded, $(O)$ debonded.

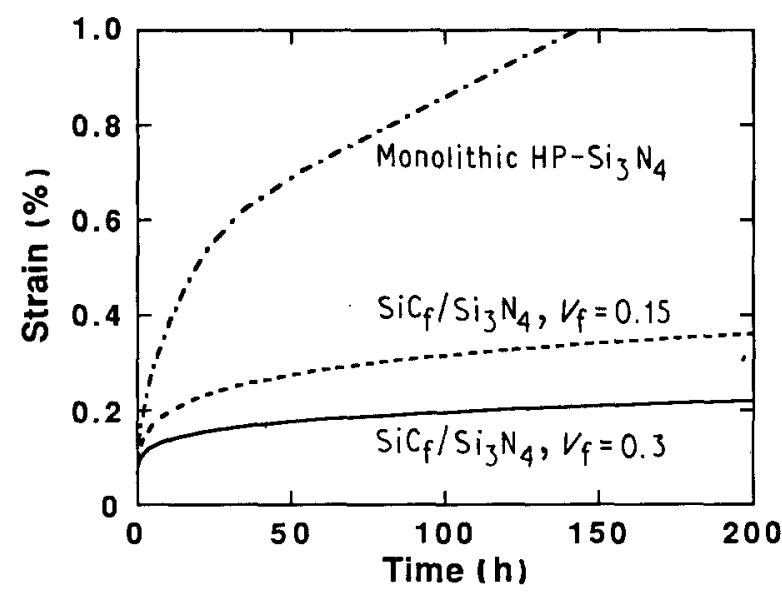

Figure 10 Finite element results showing the effect of fibre reinforcement and volume fraction on the creep deformation of unidirectional $\mathrm{HP}-\mathrm{SiC}_{\mathrm{f}} / \mathrm{Si}_{3} \mathrm{~N}_{4}$ composites at $1200^{\circ} \mathrm{C}$ and $180 \mathrm{MPa}$. The creep behaviour of monolithic HP- $\mathrm{Si}_{3} \mathrm{~N}_{4}$ is shown for comparison. The creep of monolithic HPSN was modelled using Fett et al.'s data [19] for primary creep and Kossowsky's data [20] for steadystate creep behaviour. systems (see Fig. 5). The analysis showed that the creep rate of the composite was approximately one order of magnitude lower than that of the monolithic $\mathrm{Si}_{3} \mathrm{~N}_{4}$ used for comparison. For example, at $200 \mathrm{~h}$, the creep rates are $9.3 \times 10^{-9} \mathrm{~s}^{-1}$ for monolithic $\mathrm{HP}$ $\mathrm{Si}_{3} \mathrm{~N}_{4}, 1.74 \times 10^{-9} \mathrm{~s}^{-1}$ for $\mathrm{SiC}_{\mathrm{f}} / \mathrm{Si}_{3} \mathrm{~N}_{4}$ with $V_{\mathrm{f}}=0.15$ and $8.3 \times 10^{-10} \mathrm{~s}^{-1}$ for $\mathrm{SiC}_{\mathrm{f}} / \mathrm{Si}_{3} \mathrm{~N}_{4}$ with $V_{\mathrm{f}}=0.3$. The significantly lower creep rate of the composite can be attributed to load sharing between the fibre and the matrix due to mismatch in their elastic moduli and creep rates. An increase in the fibre volume fraction from $15 \%$ to $30 \%$ resulted in a large decrease in creep rate (approximately $50 \%$ at $200 \mathrm{~h}$ ) and in total creep strain (approximately $40 \%$ at $200 \mathrm{~h}$ ).

Fig. 11 compares the predicted creep behaviour of the composite with experimental results obtained at $1200^{\circ} \mathrm{C}$ and an applied stress of $200 \mathrm{MPa}$. The predicted quasi steady-state creep behaviour was in excellent agreement with that found for the tape-cast composite. The high level of agreement is attributed to the uniform fibre distribution found in the tape-cast composite, which provides a microstructure close to the ideal fibre spacing which was assumed in the analysis. In contrast, very poor agreement was found for the dry-powder lay-up composite which exhibited a much higher creep rate and failure within $150 \mathrm{~h}$. This lack of agreement is attributed to the non-uniform fibre distribution found in the dry-powder lay-up system which can cause stress concentrations in the matrix and early matrix cracking. For both systems the analysis underestimated the primary creep rate of the composite. The apparent steady-state creep rate for the dry-powder lay up composite $\left(4.9 \times 10^{-9} \mathrm{~s}^{-1}\right)$ was approximately one order of magnitude higher than that found for the tape-cast system $\left(8.3 \times 10^{-10} \mathrm{~s}^{-1}\right)$.

Owing to the absence of steady-state creep predicted from the analytical results, the creep rate at a particular time and creep strain was evaluated to determine the predicted stress dependence of creep rate. Fig. 12 shows that the logarithmic stress dependence of creep rate was 6.4 at a constant strain of $0.15 \%$, and 1.1 at a constant time of $20 \mathrm{~h}$, respectively. The choice of a particular time did not alter the stress exponent significantly, for example, $n=0.85$ at $50 \mathrm{~h}$ and $n=0.74$ at $100 \mathrm{~h}$.

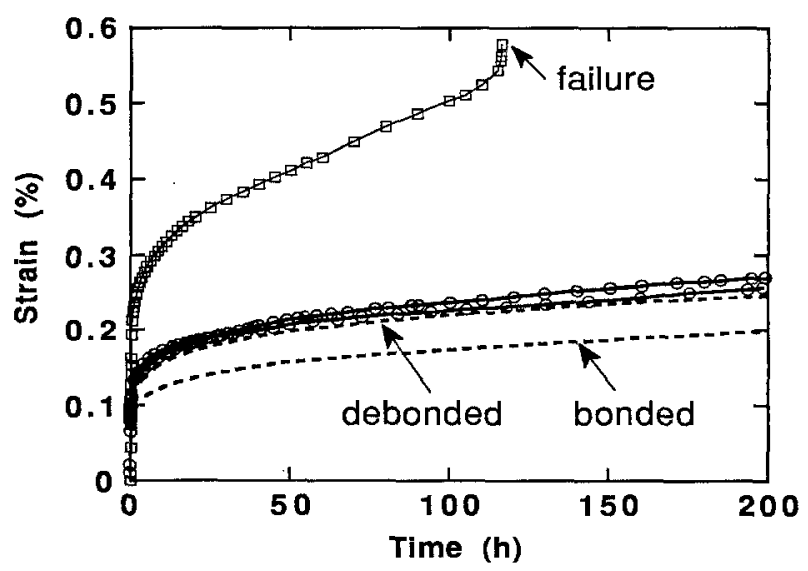

Figure $11(--\rightarrow)$ Predicted creep behaviour of unidirectional HP$\mathrm{SiC}_{\mathrm{f}} / \mathrm{Si}_{3} \mathrm{~N}_{4} \quad(30$ vol \%) compared with experimental results: (O) tape-cast, $(\square)$ dry-powder lay-up. 


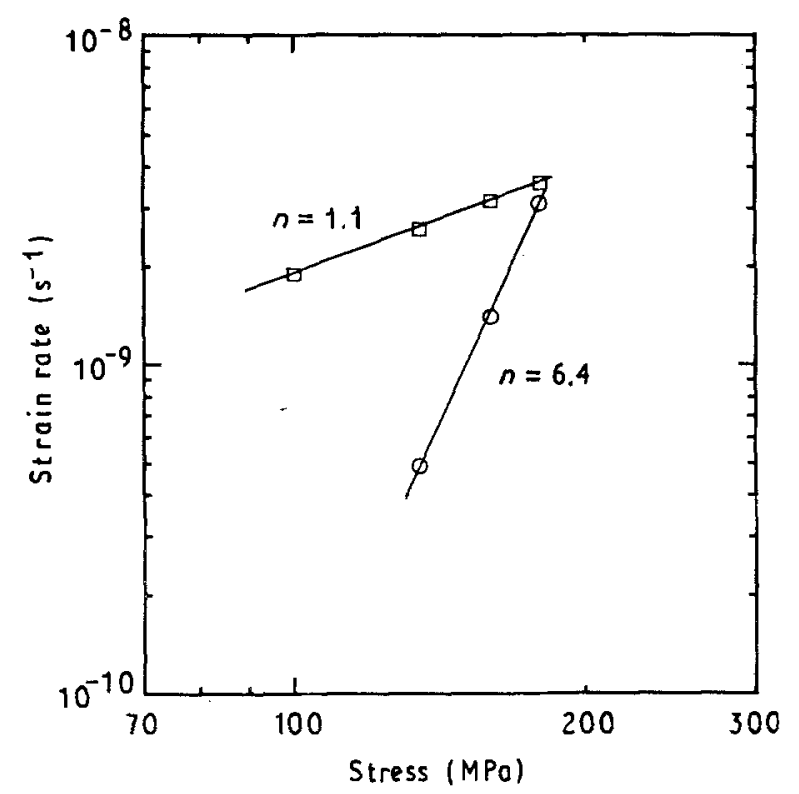

Figure 12 Stress dependence of creep rate at $1200^{\circ} \mathrm{C}$ and $(\mathrm{O}) 0.15 \%$ strain and ( $\square) 20 \mathrm{~h}$.

\subsection{Influence of matrix creep rate}

Fig. 13 shows the effect of changing the primary and steady-state creep behaviour of the matrix on the predicted creep behaviour of the composite. Decreasing the primary creep rate of the matrix, while maintaining the same steady-state creep behaviour, had little effect on the quasi steady-state behaviour of the composite. Decreasing the steady-state creep rate of the matrix by $50 \%$, while maintaining the same primary creep behaviour, decreased the quasi steadystate creep rate of the composite by only $20 \%$ at $200 \mathrm{~h}$ (see Fig. 13). This result illustrates the dominant effect that the fibre properties can have on the creep rate of fibre-reinforced CMCs. Moreover, these results sug-

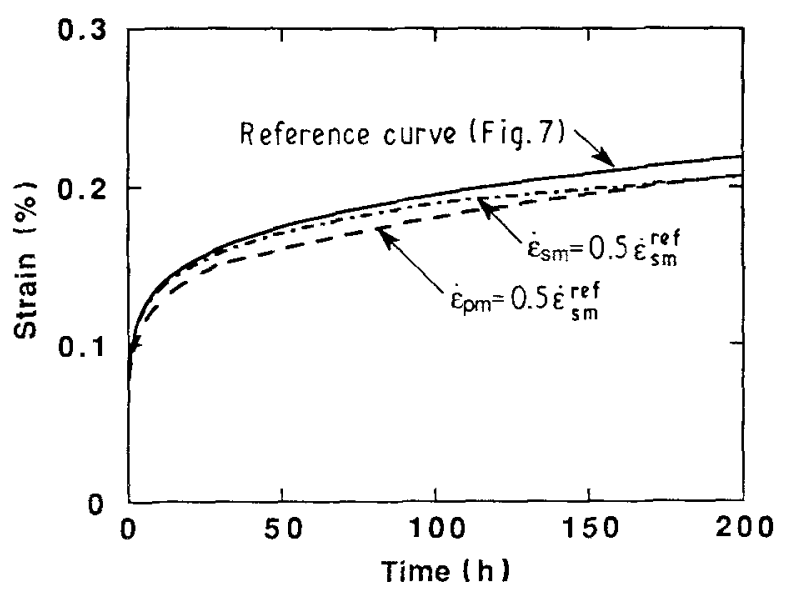

Figure 13 The effect of changing the primary and steady-state creep rates of the matrix on the overall creep behaviour of $\mathrm{HP}-\mathrm{SiC}_{\mathrm{f}} / \mathrm{Si}_{3} \mathrm{~N}_{4}$ (30 vol \%). Between 100 and $200 \mathrm{~h}$, decreasing the steady-state creep rate of the matrix by $50 \%$ reduces the quasi steady-state creep rate of the composite by approximately $20 \%$. The analysis assumed a temperature of $1200^{\circ} \mathrm{C}$ and stress of $180 \mathrm{MPa}$

initial cooling from the processing temperature of $1700^{\circ} \mathrm{C}$ to the analysis temperature of $1200^{\circ} \mathrm{C}$, an axial residual compressive stress of $90 \mathrm{MPa}$ (Fig. 9) develops in the matrix; a corresponding axial tensile stress of $210 \mathrm{MPa}$ develops in the fibre. As a consequence of the larger coefficient of thermal expansion of the fibre, a radial tensile stress of $95 \mathrm{MPa}$ develops at the interface. This radial stress is of the same order of magnitude as the stress ( $82 \mathrm{MPa}$ ) calculated from the following analytical equation for the thermal residual stress that develops normal to the fibre-matrix interface, (The equation was derived assuming a simplified coaxial composite cylinder [22])

$$
\sigma_{\mathrm{r}}=\frac{E_{\mathrm{m}} V_{\mathrm{m}}\left(\alpha_{\mathrm{f}}-\alpha_{\mathrm{m}}\right) \Delta T}{2 \lambda\left(1-v_{\mathrm{m}}\right)}
$$

$$
\lambda=\left[2-\left(1-\frac{E_{\mathrm{c}}}{E_{\mathrm{f}}}\right)\left(1-v_{\mathrm{f}}\right)+V_{\mathrm{m}}\left(v_{\mathrm{m}}-v_{\mathrm{f}}\right)-2 \frac{E_{\mathrm{c}}}{E_{\mathrm{f}}}(\beta-1)^{2}\right] / 2\left(1-v_{\mathrm{m}}\right) \beta
$$

$$
\begin{gathered}
\beta=\left(1+v_{\mathrm{f}}\right)+\left(v_{\mathrm{m}}-v_{\mathrm{f}}\right) V_{\mathrm{f}} \frac{E_{\mathrm{f}}}{E_{\mathrm{c}}} \\
E_{\mathrm{c}}=V_{\mathrm{f}} E_{\mathrm{f}}+V_{\mathrm{m}} E_{\mathrm{m}}
\end{gathered}
$$

where $\sigma_{r}$ is the radial thermal stress at the interface, and $\Delta T$ is the temperature difference upon cooling from the processing temperature. For a creep stress of $180 \mathrm{MPa}$, the average radial stress at the interface decreased from approximately $95 \mathrm{MPa}$ to $85 \mathrm{MPa}$ upon initial loading, and relaxed to approximately $5 \mathrm{MPa}$ after $20 \mathrm{~h}$ of creep (see Fig. 14). The tensile radial stress at the bonded interface became compressive after about $70 \mathrm{~h}$ of creep.

As noted earlier, for the limiting case of a perfectly bonded interface, the two-dimensional model accurately predicted the axial stresses in the fibre and matrix (within $1 \%$ of the three-dimensional analysis), but could not predict the radial and tangential stress concentrations near the fibre/matrix interface (see Fig. 14, also note that the two-dimensional axisymmetric model assumes a uniform radial stress distribution). Knowledge of these stress concentrations changes in radial stress that occur during creep a simpler two-dimensional analysis was used. Upon 

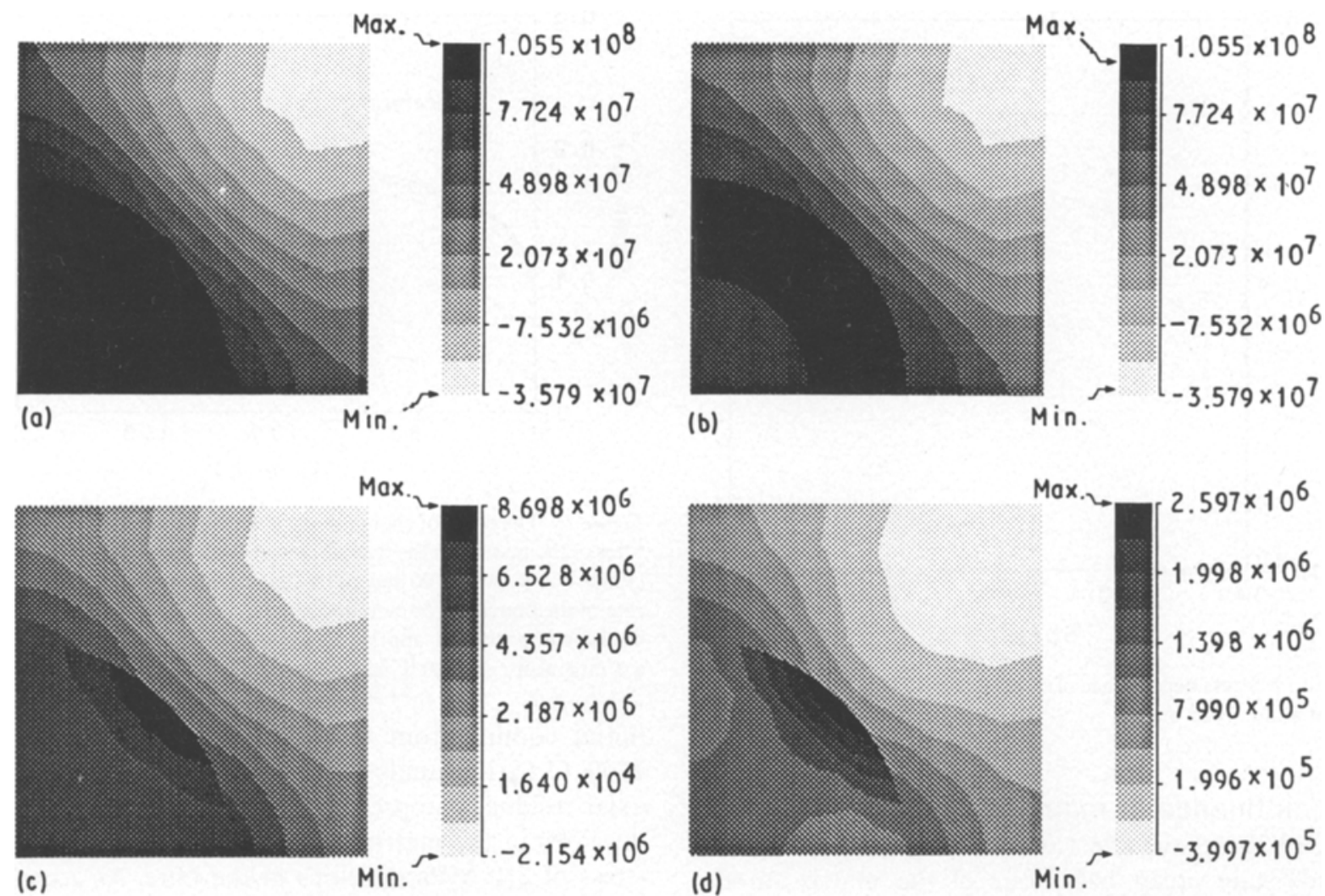

Figure 14 Change in radial stress distribution in the fibre and matrix during tensile creep at a temperature of $1200^{\circ} \mathrm{C}$ and an applied stress of $180 \mathrm{MPa}$. The analysis assumed a perfectly bonded interface. (a) $t=0 \mathrm{~h}$ (on cooling), (b) $t=0 \mathrm{~h}$ (on loading), (c) $t=20 \mathrm{~h}$, (d) $t=50 \mathrm{~h}$.

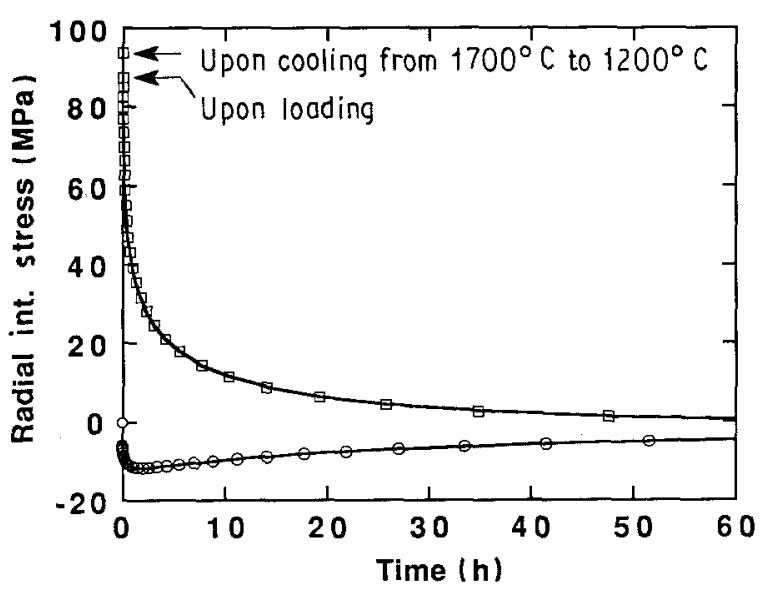

Figure 15 Relaxation of radial stress at the interface at $1200^{\circ} \mathrm{C}$ and $180 \mathrm{MPa}:(\square)$ bonded, $(\bigcirc)$ debonded, assuming no initial interface separation.

is important for the development of models used to predict the local interfacial fracture behaviour of composites.

In the debonded two-dimensional model, the fibre stress for an applied stress of $180 \mathrm{MPa}$ and $30 \mathrm{vol} \%$ fibres increased from $215 \mathrm{MPa}$ upon initial loading, to over $500 \mathrm{MPa}$ after $200 \mathrm{~h}$ of creep. It should be noted that the initial fibre stress of $215 \mathrm{MPa}$ is below the stress range for which Dicarlo's data was experimentally determined $\left(278 \leqslant \sigma_{\mathrm{f}} \leqslant 612 \mathrm{MPa}\right)$. However, for the analysis discussed here, the fibre stress increased to $280 \mathrm{MPa}$ within $30 \mathrm{~min}$ of applying the creep stress and remained, thereafter, within the stress range for which Dicarlo's data were valid.

\subsection{Influence of creep deformation on interfacial separation}

If weak bonding along the fibre/matrix interface exists, the relatively large radial tension which develops at the interface upon cooling from the processing temperature could promote interfacial debonding. For this situation, it is of interest to know how the initial interfacial separation changes during creep. A simplified two-dimensional axisymmetric model was used to investigate the radial separation of the interface. It was assumed that complete debonding between the fibre and matrix was initially present, and that thermoelastic recovery of each constituent occurred upon cooling.

The initial separation which exists at the interface in the debonded model, is directly affected by the processing and creep temperatures. Upon cooling of the billets from $1700^{\circ} \mathrm{C}$ to $25^{\circ} \mathrm{C}$, an interfacial gap of $0.28 \mu \mathrm{m}$ would exist; upon reheating to $1200^{\circ} \mathrm{C}$, the gap would decrease to $0.063 \mu \mathrm{m}$. For a boundary condition where the side of the unit cell remains parallel, but is permitted to move freely in the transverse direction (see Fig. 2c) the initial separation of $0.063 \mu \mathrm{m}$ would decrease to $0.058 \mu \mathrm{m}$ immediately after application of a $180 \mathrm{MPa}$ tensile creep stress. The interfacial gap would decrease to $0.03 \mu \mathrm{m}$ after $200 \mathrm{~h}$ of creep (see Fig. 16). However, upon unloading and cooling to room temperature, the gap would increase to $0.27 \mu \mathrm{m}$. If lateral constraint is applied to the sides of the unit cell (e.g. from cold grips, see Fig. 2d), the initial separation of $0.063 \mu \mathrm{m}$ would increase to $0.078 \mu \mathrm{m}$ upon initial loading. The gap would increase to $0.23 \mu \mathrm{m}$ after $200 \mathrm{~h}$ of creep. Upon unloading and cooling to 


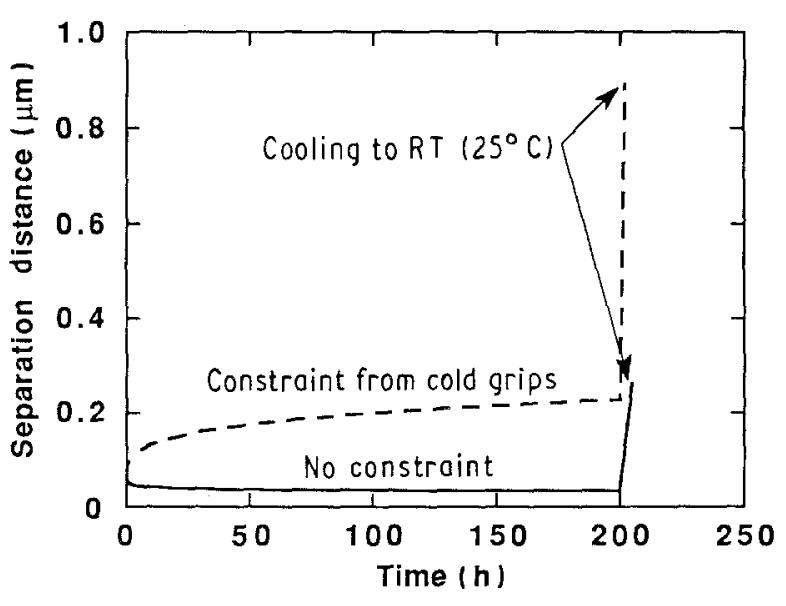

Figure 16 Interface separation normal to the fibre/matrix interface. Two cases were considered: (1) no lateral constraint (the edge of the unit cell remains plane, but is free to undergo lateral displacement) and (2) constraint from cold grips (the edge of the unit cell is constrained from lateral displacement). The analysis assumed an initially debonded interface.

room temperature, the separation would increase to $0.9 \mu \mathrm{m}$ (see Fig. 16). This result (an increase in interfacial separation) is consistent with experimental results obtained by Holmes [6] for the creep testing of $\mathrm{HP}-\mathrm{SiC}_{\mathrm{f}} / \mathrm{Si}_{3} \mathrm{~N}_{4}$ at $1350^{\circ} \mathrm{C}$.

For the case where the fibre and matrix are initially in contact, and assuming boundary conditions where the sides of the unit cell remain parallel but are permitted to move freely in the transverse direction (this would correspond to a hot-grip arrangement), the debonded interface behaves like a bonded interface under the same boundary condition. The reason for this behaviour is due to the larger Poisson's contraction and creep deformation of the matrix which keeps the interface in contact with the fibre from the onset of loading. In this case, the radial stress that develops at the interface upon loading is always compressive due to the larger Poisson's ratio contraction of the matrix. The magnitude of the radial compressive stress initially increases, and then gradually relaxes as creep continues. The initial increase in compressive radial stress is caused by the rapid primary creep rate of the matrix. An investigation that considered a composite system with a smaller Poisson's ratio for the matrix showed that the initial interfacial separation which develops upon loading would decrease as creep continued. In this case, after contact, the debonded interface would behave like an interface with frictional sliding. The decrease in the interface gap can be attributed to the rapid primary creep which occurs in the matrix even at low stress levels. The rate at which the interfacial gap decreases depends upon the difference in Poisson's ratio and the primary creep rates of the fibre and matrix.

\subsection{Creep behaviour under biaxial loading} The influence of biaxial loading on the axial creep rate of $\mathrm{HP}-\mathrm{SiC}_{\mathrm{f}} / \mathrm{Si}_{3} \mathrm{~N}_{4}$ composites was numerically studied. In the analysis, the axial stress was held constant, and a transverse stress of different magnitudes was applied to the composite. The analysis, conducted at $1200^{\circ} \mathrm{C}$, assumed perfect fibre-matrix bonding. Fig. 17 shows the predicted effect of biaxial loading on the tensile creep deformation of the composite. Maintaining the stress parallel to the fibre axis constant, the creep rate decreases as the transverse stress is increased. For example, increasing the ratio of transverse stress to axial stress from 0.67 to 1.0 decreases the $200 \mathrm{~h}$ quasi steady-state creep rate of the composite by approximately $11 \%$ and $20 \%$ of the rate for uniaxial loading alone, respectively.

The axial creep rate of the composite is related to the deviatoric stress (defined as $\sigma_{i j}^{\prime}=\sigma_{i j}-\sigma_{\mathrm{h}}$ $\delta_{i j}$ where $\sigma_{\mathrm{h}}=\frac{1}{3} \sigma_{i i}(i, j=1,2,3)$ is a hydrostatic component of the stress); a decrease in deviatoric stress reduces the overall tensile creep rate. Thus the predicted reduction in creep rate as transverse loading is applied is a consequence of the increase in hydrostatic tensile stress in the fibre and matrix. Compared to its influence on quasi steady-state creep rate, biaxial loading has a more significant influence on the primary creep rate of the composite. This difference can be attributed to the fact that the stress redistribution which takes place during creep will depend upon the magnitude of the deviatoric stress in the matrix; during primary creep the deviatoric stress changes rapidly. It should be noted that the presence of high hydrostatic stresses can accelerate microstructural damage such as the nucleation and growth of matrix cavities [23]. Thus, although the creep rate is predicted to decrease under biaxial loading, it must be kept in mind that the present analysis does not account for the influence of microstructural damage on creep rate.

\subsection{Recovery behaviour}

Experimental results indicate that $\mathrm{HP}-\mathrm{SiC}_{\mathrm{f}} / \mathrm{Si}_{3} \mathrm{~N}_{4}$ composites can undergo significant viscous or nonelastic strain recovery upon removal of the creep

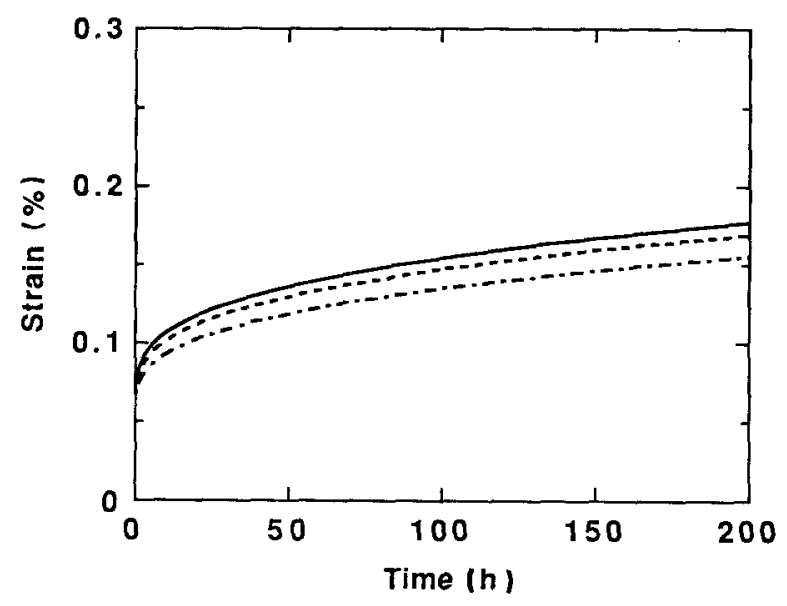

Figure 17 Effect of simultaneous transverse loading on the tensile creep behaviour of unidirectional $\mathrm{HP}-\mathrm{SiC}_{\mathrm{f}} / \mathrm{Si}_{3} \mathrm{~N}_{4}(30 \mathrm{vol} \%)$ at $1200^{\circ} \mathrm{C}$. The three-dimensional analysis assumed a bonded interface. Increasing the ratio of transverse stress to axial stress from 0.67 to 1.0 decreases the $200 \mathrm{~h}$ quasi steady-state creep rate of the composite by approximately $11 \%$ and $20 \%$ compared to uniaxial loading alone. (-) Uniaxial, $180 \mathrm{MPa}$; $(--)$ biaxial, $\sigma_{\text {axial }}=180$ $\mathrm{MPa}, \quad \sigma_{\text {trans }}=120 \mathrm{MPa} ; \quad(--)$ biaxial, $\sigma_{\text {axial }}=180 \mathrm{MPa}$, $\sigma_{\text {trans }}=180 \mathrm{MPa}$. 
stress. For example, approximately $50 \%$ of the total strain which exists after $200 \mathrm{~h}$ of creep at $1200^{\circ} \mathrm{C}$ and a stress of $200 \mathrm{MPa}$, was recovered within $25 \mathrm{~h}$ of unloading (see Fig. 18). This strain recovery is much higher than the 5\%-10\% recovery observed by Arons and Tien [24] for monolithic HPSN.

In the finite element analysis of recovery behaviour, the external load was assumed to be instantaneously removed. Immediately after unloading, the fibre and matrix experience significant tensile and compressive residual stresses, respectively (see Fig. 19). In the analysis, the compressive creep behaviour of the matrix was modelled using the same constitutive equations which were used to describe the tensile creep behaviour of the matrix prior to unloading. This assumption is not strictly valid for HPSN, because creep rates in tension are generally higher than those measured in compression, e.g. by a factor of three for HS 130 HPSN [25]. Fig. 18 compares the predicted recovery behaviour of $\mathrm{HP}-\mathrm{SiC}_{\mathrm{f}} / \mathrm{Si}_{3} \mathrm{~N}_{4}$ with the recovery behaviour which was experimentally measured at a stress of $200 \mathrm{MPa}$. Fair agreement is obtained between the predicted and experimental recovery curves.

Fig. 19 shows the evolution of axial stresses in the fibre and matrix before and after unloading for both bonded and debonded interfaces. The large difference in the stress state of the fibre and matrix found during primary creep for the two interface conditions diminishes as the creep rate approaches the quasi steadystate regime. Prior to unloading after $200 \mathrm{~h}$ of creep, the axial stresses in the fibre and matrix are independent of the interfacial condition. Hence, similar elastic and creep-recovery behaviour is predicted for both cases. The magnitude of the elastic-recovery in the fibre and matrix which occurs immediately after unloading was the same as that which occurs upon initial loading. The reason for this is that the elastic moduli of the fibre and matrix were assumed to be constant during creep - in actual creep experiments the moduli may decrease as a consequence of microstructural damage accumulation.

According to Dicarlo [11], the creep and creeprecovery behaviour of SCS-6 SiC fibres is entirely anelastic for the stress and temperature ranges invest-

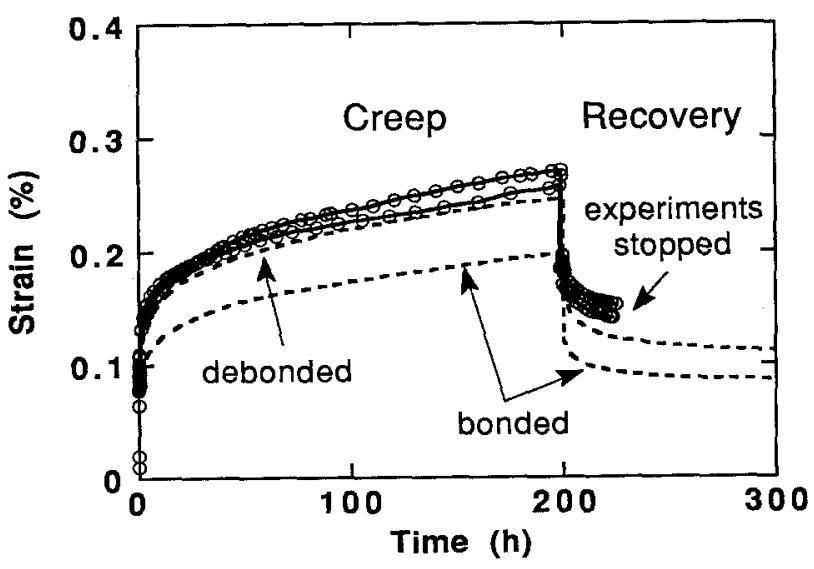

Figure 18 Comparison of (- - ) predicted and $(O)$ experimental recovery behaviour of $\mathrm{HP}-\mathrm{SiC}_{\mathrm{f}} / \mathrm{Si}_{3} \mathrm{~N}_{4}(30 \mathrm{vol} \%)$ at $1200^{\circ} \mathrm{C}$ and 200 $\mathrm{MPa}$. Approximately $50 \%$ of the total strain was recovered within $25 \mathrm{~h}$ of unloading.

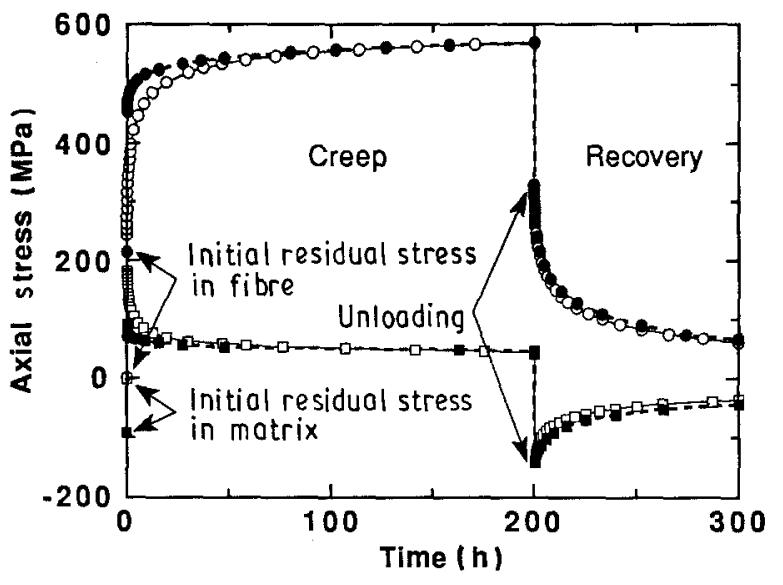

Figure 19 Change in axial stresses in the fibre and matrix during tensile creep and creep-recovery of $\mathrm{HP}-\mathrm{SiC}_{\mathrm{f}} / \mathrm{Si}_{3} \mathrm{~N}_{4}(30 \mathrm{vol} \%$ ): bonded interface ( $\boldsymbol{O}$, fibre stress; $\mathbf{D}$, matrix stress) and debonded interface ( $O$, fibre stress; $\square$, matrix stress). The analysis assumed a temperature of $1200^{\circ} \mathrm{C}$ and creep stress of $200 \mathrm{MPa}$.

igated. The controlling mechanism of creep in SCS-6 $\mathrm{SiC}$ fibres is grain-boundary sliding between $\beta-\mathrm{SiC}$ grains which is limited in motion due to the build-up of internal stresses in free silicon located at grainboundary intersections [11]. Internal stresses are developed either by $\beta$-SiC grain growth during the chemical vapour deposition process or by the thermal expansion mismatch between free silicon and $\beta-\mathrm{SiC}$. Upon unloading, the internal stresses force the grains to slide back to their original positions resulting in recovery of the fibres. According to Arons and Tien [24], the recovery of monolithic HPSN is controlled by relaxation of intragranular elastic stresses which are resisted by capillary adhesion of a glassy liquidphase at grain-boundary intersections. This recovery behaviour can be modelled by a linear-viscoelastic model with a spectrum of retardation times [24].

In addition to the intrinsic recovery of the constituent phases mentioned above, the present analysis shows that recovery in fibre-reinforced CMCs is also driven by changes in the residual stresses in the fibre and matrix. The tensile residual stress which develops in the fibres upon unloading would cause in situ tensile creep of the fibres, whereas the compressive residual stress which develops in the matrix upon unloading leads to in situ compressive creep of the matrix. If the compressive creep rate of the matrix is greater than the tensile creep rate of the fibres, the composite will tend to contract back toward its original position. This contraction is accompanied by a redistribution of stress between the fibres and matrix based upon internal force equilibrium.

\subsubsection{Implications of creep recovery on post-creep tensile behaviour}

The magnitude of the compressive residual stress in the matrix will influence the monotonic tensile behaviour of the composite. For example, a high compressive stress in the matrix will suppress matrix cracking, causing an apparent increase in the proportional limit of the composite. Moreover, for equilibrium, an increase in compressive matrix stress must be balanced 
by higher tensile stresses in the fibres. If the composite strength is dominated by fibre strength, the higher residual tensile stress in the fibres will lead to a decrease in the ultimate strength of the composite. After creep deformation, the axial compressive stress which exists in the matrix immediately after unloading is higher (more compressive) than the compressive stress present in a virgin specimen. Moreover, the tensile stress in the fibres immediately after unloading is higher than the tensile residual stress present in virgin specimens (see Fig. 19). These predictions, based upon the finite element results, are consistent with recent experimental results which show that the proportional limit increases, and the ultimate strength decreases, after long-duration fatigue testing of unidirectional $\mathrm{HP}-\mathrm{SiC}_{\mathrm{f}} / \mathrm{Si}_{3} \mathrm{~N}_{4}$ composites under a tensile mean stress [18]. The present analysis also suggests that after tensile creep (or fatigue loading under a tensile mean stress), the proportional limit of HP$\mathrm{SiC}_{\mathrm{f}} / \mathrm{Si}_{3} \mathrm{~N}_{4}$ will be lower than that for virgin material if significant recovery has occurred prior to reloading in monotonic tension (note that after unloading the compressive residual stress in the matrix rapidly relaxes, see Fig. 19).

\section{Conclusions}

The tensile creep behaviour of a unidirectional HP$\mathrm{SiC}_{\mathrm{f}} / \mathrm{Si}_{3} \mathrm{~N}_{4}$ ceramic matrix composite was analysed using finite element techniques. The following conclusions can be drawn regarding the tensile creep and creep-recovery behaviour at $1200^{\circ} \mathrm{C}$.

1. For stress levels below the matrix cracking stress, finite element techniques which utilize primary creep, together with the elastic and steady-state creep properties of both constituents, can provide reasonable predictions of tensile creep and creep-recovery behaviour.

2. Assuming perfect bonding in a three-dimensional rectangular unit cell, local concentrations in the radial and tangential stresses near the fibre/matrix interface develop during long-term creep. Upon cooling of the composite billets after processing, a tensile radial stress develops in the vicinity of the interface. This tensile residual stress rapidly relaxes during creep.

3. During long term creep, the matrix sheds load to the more creep resistant fibres. For hot-pressed SCS- 6 $\mathrm{SiC}_{\mathrm{f}} / \mathrm{Si}_{3} \mathrm{~N}_{4}$ composites, reductions in overall creep rate can be most readily accomplished by increasing the volume fraction of fibres. The change in stress state caused by load shedding can have a significant influence on post-creep tensile behaviour.

4. The simultaneous addition of a transverse load, while maintaining the axial load constant, decreases the overall axial creep rate of the composite. For example, for equal biaxial stresses of $180 \mathrm{MPa}$, the quasi steady-state creep rate of the composite at $200 \mathrm{~h}$ decreases by approximately $20 \%$ compared to uniaxial loading alone.
5. Both the predicted and experimental results showed that $50 \%$ of the total creep strain which accumulated after $200 \mathrm{~h}$ at a stress of $200 \mathrm{MPa}$ is recovered within $25 \mathrm{~h}$ of unloading. This recovery is significantly higher than the recovery which has been reported in the literature for monolithic HPSN (NC 132). The mechanism of creep-recovery in the composite is related to relaxation of the residual stresses which develop in the fibre and matrix upon unloading.

\section{Acknowledgements}

The authors thank Dr Jim Dicarlo, NASA Lewis Research Center, for discussions on the creep behaviour of SCS-6 fibres, and Professor J. Wayne Jones for consultations concerning the experimental results.

\section{References}

1. G. C. WEI and P. F, BECHER, Amer. Ceram. Soc. Bull. 64 (1985) 298.

2. J. J. BRENNAN and K. M. PREWO, J. Mater. Sci. 17 (1982) 2371 .

3. R. T. BHATT, NASA Technical Report 85-C-14 (1985).

4. H. KODAMA, H. SAKAMOTO, and T. MiYOSHI, J. Amer. Ceram. Soc. 72 (1989) 551

5. F. ABBE, J. VICENS and J. L. CHERMANT, J. Mater. Sci. Lett. 8 (1989) 1026.

6. J. W. HOLMES, J. Mater. Sci. 26 (1991) 1808.

7. M. MClEAN, Mater. Res. Soc. Symp. Proc. 120 (1988)

8. H. LILHOLT, Compos. Sci. and Technol. 29 (1985) 277

9. T. L. DRAGON and W. D. NIX, Acta Metall, Mater. 38 (1990) 1941.

10. J. R. BROCKENBROUGH, S. SURESH and H. A WIENECKE, ALCOA Laboratories Technical Report no. 57-89-35 (April 1990).

11. J. A. DICARLO, J. Mater. Sci. 21 (1986) 217.

12. D. C. LARSON, J. W. ADAMS, L. R. JOHNSON, A. P. S TEOTIA and L. G. HILL, in "Ceramic Materials for Advanced Heat Engines; Technical and Economical Evaluation" (Noyes, Park Ridge, NJ, 1985).

13. J. W. LA Ughner and R. T. Bhat T, J. Amer. Ceram. Soc. 72 (1989) 2017.

14. G. MORSCHER, P. PIROUZ and A. H. HEUER, ibid. 73 (1990) 713

15. "ABAQUS Manual," (Hibbitt, Karlson and Sorensen Inc., Providence, RI, 1989).

16. A. H. CHOKSHI, and J. R. PORTER, J. Amer. Ceram. Soc. 68 (1985) C-144.

17. R. D. NIXON, S. CHEVACHAROENKUL, M. L. HUCKABEE, S. T. BULJAN and R. F. DAVIS, Mater.Res. Soc. Symp. Proc. 78 (1987) 295.

18. J. W. HOLMES, J. Amer. Ceram. Soc. 74 (1991) 1639.

19. T. FETT, G. HIMSOLT and D. MUNZ, Adv. Ceram. Mater. 1 (1986) 179

20. R. KOSSOWSKY, D. G. MILLER and E. S. DIAZ, J. Mater. Sci. 10 (1975) 983.

21. J. W. HOLMES, J. Compos. Mater. 26 (1992) 915.

22. B. BUDIANSKY, J. W. HUTCHINSON and A. G. EVANS, J. Mech. Phys. Solids 34 (1986) 167

23. J. L. CHA BOCHE, J. Appl. Mech. 55 (1988) 65.

24. R. M. ARONS and J. K. TIEN, J. Mater. Sci. 15 (1980) 2046.

25. M. S. SELTZER, Amer. Ceram. Soc. Bull. 56 (1977) 418.

Received 20 June

and accepted 16 December 1991 